\title{
In Vitro Regeneration of Capsicum (Capsicum annuum L.) from Cotyledon Explants
}

\author{
Vivek Hegde $^{1,3 *}$, P.S. Partap ${ }^{1}$ and R.C. Yadav ${ }^{2}$ \\ ${ }^{1}$ Department of Vegetable Science, \\ CCS Haryana Agricultural University, Hisar-125 004, Haryana, India \\ ${ }^{2}$ Department of Molecular Biology and Biotechnology \\ CCS Haryana Agricultural University, Hisar-125 004, Haryana, India \\ ${ }^{3}$ Division of Crop Improvement, \\ ICAR- Central Tuber Crops Institute, Thiruvananthapuram, Kerala, India \\ *Corresponding author
}

\section{A B S T R A C T}

Pre-requisite for any plant biotechnological approach is development of an efficient plant regeneration system in that crop. In this regard the in vitro regeneration was achieved by

\section{Keywords}

In vitro regeneration, Cotyledon, Capsicum, Tissue culture.

\section{Article Info}

\section{Accepted:}

04 April 2017

Available Online:

10 May 2017 using cotyledon explants from aseptically raised seedlings of popular Capsicum $\mathrm{F}_{1}$ hybrids Bharat and Indra. Seeds of both hybrids were exposed to different treatments for proper germination, were decontaminated and sown in vitro on half-strength MS medium. The seed soaked in distilled water along with $2 \mathrm{mg} / \mathrm{l} \mathrm{GA}$ for two days prior to sowing had more pronounced effect on both capsicum hybrids recording maximum germination ( 90.45 and $84.59 \%$, respectively) in minimum number of days (9.67 days and 10.33 days, respectively). Regeneration potential of cotyledonary explants touching the medium both abaxial and adaxial sides was examined. Tissue culture responses varied with the genotypes, side of explants touching the medium and combinations of growth regulators used. Regeneration per cent $(96.30 \%)$, number of shoots per explants (4.56) and per cent shoot elongation $(82.10 \%)$ was maximum in hybrid Indra from cotyledon explant having abaxial side in contact with growing medium supplemented with $7.5 \mathrm{mg} / \mathrm{l}$ zeatin along with $2.0 \mathrm{mg} / \mathrm{l} \mathrm{GA}$. When regenerated shoots cultured on MS media supplemented with 0.5 $\mathrm{mg} / \mathrm{l}$ IBA produced $100 \%$ rooting in both the hybrids. The survival percentage of regenerated plantlets during hardening in pots containing sterile mixture of 1:1 coco-peat and vermiculite was higher in Indra (92.31\%) as compared to Bharat $(85.71 \%)$.

\section{Introduction}

Capsicum (Capsicum annuum L.) is one of the most important vegetable crops in the world and commonly known as pepper, sweet pepper or bell pepper, belongs to the family Solanaceae. This indispensable item of kitchen occupying an important place in Indian diet is consumed daily in one or the other form as a condiment and spice, vegetable, adding colour, flavour, pungency and piquancy to various foodstuffs. It is an excellent source of vitamins A, B-complex, C, $\mathrm{E}$ and is rich in minerals like molybdenum, manganese, folate and potassium (Simonne et al., 1997). 
In spite of 400 different capsicum varieties found grown all over the world, the vulnerability of these genotypes consequent to the abiotic and biotic stresses including the extremes of temperature, moisture, light, nutrients and $\mathrm{pH}$ among others and the insect pests, fungi, bacteria and viruses has drastically restricted their yield potential and quality (Ochoa and Ramirez, 2001; Egea et al., 2002; Suzuki and Mori, 2003 and Venkataiah et al., 2003). Although, the conventional plant breeding combined with improved agricultural practices has upgraded capsicum crop production, quality and use remarkably, yet the restricted gene pool or range of organisms among which genes can be transferred, has placed a limit to this technology.

Hence, gradually the biotechnology encompassing plant tissue culture and genetic engineering is becoming a functional tool of classical plant breeding to boost the crop improvement programs. In vitro plant regeneration from cells, tissues and organ cultures, which is a fundamental process of biotechnology application in plant propagation, plant breeding and genetic improvement would serve the main purposes of micro-propagation of elite plants, maintenance of male sterile lines, selection of soma-clonal variants, mass multiplication of pollen-derived haploid plants, selection of plants against biotic and abiotic stresses and the genetic transformation.

The regeneration responses depend on various factors like genotype, explants, growth regulators and their concentrations etc. (Dabauza and Pena, 2001). However, despite the economic significance of capsicum, its whole plant regeneration has not progressed akin to vegetables crops like tomato and potato having greater plant regeneration capability from cells, tissues or organs.

\section{Materials and Methods}

Among the popular $F_{1}$ hybrids of sweet pepper largely being grown by the farmers of the region, the hybrids Bharat and Indra were chosen for the present study. The seeds were first washed with tween-20 and exposed to different treatments for proper germination. Seeds soaked in distilled water for 2 days at room temperature and at $4^{\circ} \mathrm{C}$, distilled water with $2 \mathrm{mg} / \mathrm{l} \quad \mathrm{GA}_{3}$ for 2days at room temperature and at $4^{\circ} \mathrm{C}$, also fresh seeds were taken to laminar-airflow cabinet and surface sterilized with 0.1 per cent mercuric chloride $\left(\mathrm{HgCl}_{2}\right)$ for 5 to 6 minutes and finally rinsed 4 to 5 times with sterile double distilled water to remove the traces of $\mathrm{HgCl}_{2}$. Surface sterilized seeds were aseptically inoculated on half strength solid MS basal medium and incubated at $25 \pm 2{ }^{\circ} \mathrm{C}$ under $16 \mathrm{~h}$ light and $8 \mathrm{~h}$ dark photoperiod for raising the seedlings. These in vitro grown, 5-7 day old seedlings were used to harvest explants for regeneration purpose.

The 0.4 to $0.6 \mathrm{~cm}$ cotyledon explants were inoculated horizontally on MS basal medium containing three per cent sucrose, 0.8 per cent agar supplemented with different concentrations and combinations of growth regulators. Regeneration potential of both abaxial and adaxial sides of the cotyledonary explants was examined (Plate 1A). After inoculation of explants in Petri-dishes containing media with different treatments, these were sealed properly with the parafilm strips to protect from contamination.

Cultures were incubated in culture room at $25 \pm 2{ }^{\circ} \mathrm{C}$ temperature under a photoperiod of $16 \mathrm{~h}$ light and $8 \mathrm{~h}$ dark. The well elongated individual shoots generated and obtained from shooting medium were separated and transferred to MS medium supplemented with $0.5 \mathrm{mg} / \mathrm{l} \mathrm{IBA}$ for root induction. 
Plantlets grown were carefully removed from the culture bottles without damaging their root systems and washed properly under running tap water to remove the traces of medium sticking to the roots. The rooted shoots (plantlets) were transferred to pots containing the sterile mixture of coco-peat and vermiculite (1:1) for proper establishment. The nutrients were supplied through the application of liquid MS basal medium without sucrose, at 5 day intervals. Each pot was covered with a polythene bag to maintain humidity around the plants and kept in culture room at $25 \pm 2{ }^{\circ} \mathrm{C}$ temperature, under photoperiod of $16 \mathrm{~h}$ light and $8 \mathrm{~h}$ dark. Within 6-7 days, the polythene bags were removed and after 14 days of acclimatization under laboratory condition, plantlets were transferred to shade net in big size pot containing soil: sand: farmyard manure $(1: 1: 1)$.

Seed germination percentage and the number of days taken from the date of seed inoculation to germination in various treatments were expressed as mean number of days. The per cent regeneration, elongated shoots per explants, per cent shoot elongation and per cent survivals of regenerated plants in soil were assessed. The mean and standard errors were worked out from triplicate data obtained from various treatments. The per cent data transformed using angular transformation and analyzed following Completely Randomized Design (CRD).

\section{Results and Discussion}

In the present study when fresh seeds of two $\mathrm{F}_{1}$ capsicum hybrids namely, Bharat and Indra, were placed in vitro on MS culture medium without any pre-sowing treatment, exhibited delayed and very low seed germination i.e. 23.67 and 20.00 per cent, respectively. The seed germination due to the pre-sowing seed treatments improved and ranged from $42.44 \%$ to $90.45 \%$. Seeds soaked in distilled water before sowing had positive influence on germination percentage as well as number of days taken for germination while, seed soaked in distilled water along with $\mathrm{GA}_{3}$ at $2 \mathrm{mg} / \mathrm{l}$ for two days prior to sowing had more pronounced effect on both capsicum hybrids recording maximum germination in minimum number of days (Table 1). In earlier studies, Watkins and Cantlife (1983) and Watkins et al., (1985) found that enclosure of radical tips by non starchy endospermic tissues might placed mechanical barrier to the growing embryo and contributed to slow and erratic germination of pepper seeds. External application of $\mathrm{GA}_{3}$ might weaken the endosperm and triggered the germination. Watkins et al., (1985) and Groot and Karssen (1987) reported that $\mathrm{GA}_{3}$ mediated enzymic activity might participate in weakening process of endosperms in seeds prior to germination. Similarly, Andreoli and Khan (1999) described that seed treatment with $\mathrm{GA}_{3}$ might efficiently digest the endosperm cells by $\mathrm{GA}_{3}$ induced enzymes and reduced the mechanical restraints against germination of pepper seeds.

Genotype is one of the main factors that influence the organogenic response of in vitro cultures in different plant species. Per cent regeneration, number of shoots per explants and per cent elongation was maximum in hybrid Indra as compared to Bharat, on MS medium supplemented with $7.5 \mathrm{mg} / \mathrm{l}$ zeatin along with $2.0 \mathrm{mg} / \mathrm{l} \mathrm{GA}_{3}$ and $7.5 \mathrm{mg} / \mathrm{l}$ kinetin along with $2.0 \mathrm{mg} / \mathrm{l} \mathrm{GA}{ }_{3}$ (Tables 3 and 5). But, hybrid Bharat responded better than Indra on MS medium containing $10.0 \mathrm{mg} / \mathrm{l}$ BAP along with $2.0 \mathrm{mg} / \mathrm{l} \mathrm{GA}_{3}$ and $5.0 \mathrm{mg} / \mathrm{l}$ TDZ along with $2.0 \mathrm{mg} / 1 \mathrm{GA}_{3}$ (Table 2). These results are in conformity with the previous reports. Organogenic capacity differences have been observed in different chilli pepper genotypes (Christopher and Rajam, 1994), cultivars (Ezura et al., 1993; 
Szasz et al., 1995; Ramirez and Ochoa, 1996), and species (Christopher and Rajam, 1996). Recent studies have also supported the influence of genotype on organogenic capacity, for example, Mathew (2002) observed better regeneration response in cv. Byadagi Dabbi compared to Arka Lohit. Venkataiah et al., (2003) reported TDZ mediated organogenesis in 10 pepper cultivars and the extent of the response depended upon the genotype specifically. Valadez et al., (2009) reported a protocol for in vitro regeneration of four different types of chilli genotypes that varied in their organogenic responses. Kumar and Tata (2010) obtained better in vitro plant regeneration from variety X-235. Kumar et al., (2012) studied regeneration of red pepper cultivars and observed variable degree of regeneration. Marta and Pawel (2015) observed organogenesis in the 3 genotypes representing C. annuum $\mathrm{L}$. was similar and considerably lower for line SF9 derived from an interspecific hybrid $(C$. frutescens $\mathrm{L} . \times C$. annuиm). Orientation of cotyledon explants resulted significant effect on plant regeneration. Abaxial side of cotyledonary explants having the contact with growing medium responded better than adaxial side of cotyledons (Plate 1). However, the plant regeneration response was variable on MS medium supplemented with different concentrations of growth regulators. Cotyledon explants of hybrid Indra having abaxial side in contact with the growing medium supplemented with $7.5 \mathrm{mg} / 1$ zeatin along with $2.0 \mathrm{mg} / \mathrm{G} \mathrm{GA}_{3}$ recorded maximum per cent regeneration $(78.9 \%)$, more number of elongated shoots per explant (2.4) and highest per cent shoot elongation $(65.0 \%)$ (Table 5). While, the hybrid Bharat reported maximum per cent regeneration (75.7\%), more number of elongated shoots per explant (2.4) and highest per cent shoot elongation $(64.7 \%)$ on cotyledon explants having abaxial side in contact with growing medium containing 10.0 at $\mathrm{mg} / \mathrm{l}$ zeatin along with 2.0 $\mathrm{mg} / \mathrm{l} \mathrm{GA} 3$ (Table 5). In a comparative study of in vitro capsicum regeneratin, Mathew (2002), Shivegowda et al., (2002), Mok and Norzulaani (2007) and Khurana et al., (2011) reported best regeneration in cotyledonary explants.

Table.1 Effect of different seed treatments on in vitro seed germination of two Capsicum hybrids used in the study

\begin{tabular}{|l|c|c|c|c|}
\hline \multicolumn{1}{c|}{$\begin{array}{c}\text { Seed treatments before } \\
\text { sowing seeds in vitro }\end{array}$} & \multicolumn{2}{c|}{$\begin{array}{c}\text { Days taken to } \\
\text { seed germination }\end{array}$} & $\begin{array}{c}\text { Seed germination } \\
\text { percentage }\end{array}$ \\
\cline { 2 - 5 } & Bharat & Indra & Bharat & Indra \\
\hline Sowing of fresh seeds in vitro- (no seed & 29.00 & 32.67 & 23.67 & 20.00 \\
treatment)- as a Control & \pm 0.58 & \pm 0.67 & \pm 1.45 & \pm 2.31 \\
\hline Seed soaked in distilled water for two days & 25.00 & 26.33 & 53.89 & 42.44 \\
at room temperature & \pm 0.58 & \pm 0.88 & \pm 1.10 & \pm 1.24 \\
\hline Seed soaked in distilled water for two days & 24.33 & 25.00 & 55.14 & 42.59 \\
at $4^{\circ} \mathrm{C}$ & \pm 0.33 & \pm 0.58 & \pm 0.94 & \pm 1.33 \\
\hline Seed soaked in distilled water with $\mathrm{GA}_{3}$ at & 10.67 & 11.67 & 83.49 & 89.14 \\
$2 \mathrm{mg} / \mathrm{l}$ for 2 days at room temperature & \pm 0.33 & \pm 0.33 & \pm 0.97 & \pm 1.51 \\
\hline Seed soaked in distilled water with $\mathrm{GA}_{3}$ at & 9.67 & 10.33 & 84.59 & 90.45 \\
$2 \mathrm{mg} / \mathrm{l} \mathrm{for} \mathrm{two} \mathrm{days} \mathrm{at} 4^{\circ} \mathrm{C}$ & \pm 0.33 & \pm 0.33 & \pm 1.09 & \pm 0.81 \\
\hline $\mathrm{CD}$ at $5 \%$ & 1.43 & 1.90 & 3.58 & 4.86 \\
\hline
\end{tabular}


Table.2 Effect of MS medium with BAP \pm NAA/GA 3 on regeneration of cotyledon explants of Capsicum hybrids Bharat and Indra having abaxial as well as adaxial side in contact with the growing medium

\begin{tabular}{|c|c|c|c|c|c|c|c|c|c|c|c|c|c|c|}
\hline \multirow{2}{*}{\multicolumn{3}{|c|}{$\begin{array}{c}\text { MS + growth regulators } \\
(\mathrm{mg} / \mathrm{l})\end{array}$}} & \multicolumn{6}{|l|}{ Bharat } & \multicolumn{6}{|l|}{ Indra } \\
\hline & & & \multicolumn{2}{|c|}{ Per cent Regeneration } & \multicolumn{2}{|c|}{$\begin{array}{c}\begin{array}{c}\text { Elongated shoots per } \\
\text { explant }\end{array} \\
\end{array}$} & \multicolumn{2}{|c|}{ Per cent shoot elongation } & \multicolumn{2}{|c|}{ Per cent Regeneration } & \multicolumn{2}{|c|}{$\begin{array}{c}\text { Elongated shoots per } \\
\text { explant }\end{array}$} & \multicolumn{2}{|c|}{$\begin{array}{l}\text { Per cent shoot } \\
\text { elongation }\end{array}$} \\
\hline BAP & NAA & $\mathbf{G A}_{3}$ & abaxial & adaxial & abaxial & adaxial & abaxial & adaxial & abaxial & adaxial & abaxial & adaxial & abaxial & adaxial \\
\hline 2.5 & 0.0 & 0.0 & $\begin{array}{c}27.16 \\
(31.4 \pm 0.8)\end{array}$ & $\begin{array}{c}0.00 \\
(0.0 \pm 0.0)\end{array}$ & $\begin{array}{c}0.00 \\
(1.0 \pm 0.0)\end{array}$ & $\begin{array}{c}0.00 \\
(1.0 \pm 0.0)\end{array}$ & $\begin{array}{c}0.00 \\
(0.0 \pm 0.0)\end{array}$ & $\begin{array}{c}0.00 \\
(0.0 \pm 0.0)\end{array}$ & $\begin{array}{c}17.28 \\
(24.5 \pm 1.0)\end{array}$ & $\begin{array}{c}0.00 \\
(0.0 \pm 0.0)\end{array}$ & $\begin{array}{c}0.00 \\
(1.0 \pm 0.0)\end{array}$ & $\begin{array}{c}0.00 \\
(1.0 \pm 0.0)\end{array}$ & $\begin{array}{c}0.00 \\
(0.0 \pm 0.0)\end{array}$ & $\begin{array}{c}0.00 \\
(0.0 \pm 0.0)\end{array}$ \\
\hline 2.5 & 0.2 & 0.0 & $\begin{array}{c}12.35 \\
(20.5 \pm 1.1)\end{array}$ & $\begin{array}{c}0.00 \\
(0.0 \pm 0.0)\end{array}$ & $\begin{array}{c}0.00 \\
(1.0 \pm 0.0)\end{array}$ & $\begin{array}{c}0.00 \\
(1.0 \pm 0.0)\end{array}$ & $\begin{array}{c}0.00 \\
(0.0 \pm 0.0)\end{array}$ & $\begin{array}{c}0.00 \\
(0.0 \pm 0.0)\end{array}$ & $\begin{array}{c}7.41 \\
(15.8 \pm 0.0)\end{array}$ & $\begin{array}{c}0.00 \\
(0.0 \pm 0.0)\end{array}$ & $\begin{array}{c}0.00 \\
(1.0 \pm 0.0)\end{array}$ & $\begin{array}{c}0.00 \\
(1.0 \pm 0.0)\end{array}$ & $\begin{array}{c}0.00 \\
(0.0 \pm 0.0)\end{array}$ & $\begin{array}{c}0.00 \\
(0.0 \pm 0.0)\end{array}$ \\
\hline 2.5 & 0.0 & 2.0 & $\begin{array}{c}28.40 \\
(32.2 \pm 0.8) \\
\end{array}$ & $\begin{array}{c}0.00 \\
(0.0 \pm 0.0) \\
\end{array}$ & $\begin{array}{c}0.33 \\
(1.2 \pm 0.0) \\
\end{array}$ & $\begin{array}{c}0.00 \\
(1.0 \pm 0.0) \\
\end{array}$ & $\begin{array}{c}18.52 \\
(25.2 \pm 2.9) \\
\end{array}$ & $\begin{array}{c}0.00 \\
(0.0 \pm 0.0) \\
\end{array}$ & $\begin{array}{c}17.28 \\
(24.5 \pm 1.0) \\
\end{array}$ & $\begin{array}{c}0.00 \\
(0.0 \pm 0.0) \\
\end{array}$ & $\begin{array}{c}0.00 \\
(1.0 \pm 0.0) \\
\end{array}$ & $\begin{array}{c}0.00 \\
(1.0 \pm 0.0) \\
\end{array}$ & $\begin{array}{c}0.00 \\
(0.0 \pm 0.0) \\
\end{array}$ & $\begin{array}{c}0.00 \\
(0.0 \pm 0.0) \\
\end{array}$ \\
\hline 5.0 & 0.0 & 0.0 & $\begin{array}{c}51.85 \\
(46.1 \pm 0.0) \\
\end{array}$ & $\begin{array}{c}12.35 \\
(20.5 \pm 1.1) \\
\end{array}$ & $\begin{array}{c}0.89 \\
(1.4 \pm 0.0) \\
\end{array}$ & $\begin{array}{c}0.00 \\
(1.0 \pm 0.0) \\
\end{array}$ & $\begin{array}{c}28.33 \\
(32.2 \pm 0.0) \\
\end{array}$ & $\begin{array}{c}0.00 \\
(0.0 \pm 0.0) \\
\end{array}$ & $\begin{array}{c}45.68 \\
(42.5 \pm 0.7) \\
\end{array}$ & $\begin{array}{c}19.75 \\
(26.4 \pm 0.9) \\
\end{array}$ & $\begin{array}{c}0.56 \\
(1.3 \pm 0.1) \\
\end{array}$ & $\begin{array}{c}0.00 \\
(1.0 \pm 0.0) \\
\end{array}$ & $\begin{array}{c}24.44 \\
(29.6 \pm 0.4) \\
\end{array}$ & $\begin{array}{c}0.00 \\
(0.0 \pm 0.0) \\
\end{array}$ \\
\hline 5.0 & 0.2 & 0.0 & $\begin{array}{c}37.04 \\
(37.5 \pm 0.0)\end{array}$ & $\begin{array}{c}4.94 \\
(12.7 \pm 1.6)\end{array}$ & $\begin{array}{c}0.33 \\
(1.2 \pm 0.0)\end{array}$ & $\begin{array}{c}0.00 \\
(1.0 \pm 0.0)\end{array}$ & $\begin{array}{c}9.26 \\
(17.7 \pm 0.9)\end{array}$ & $\begin{array}{c}0.00 \\
(0.0 \pm 0.0)\end{array}$ & $\begin{array}{c}29.63 \\
(33.0 \pm 0.0)\end{array}$ & $\begin{array}{c}6.17 \\
(14.2 \pm 1.6)\end{array}$ & $\begin{array}{c}0.11 \\
(1.1 \pm 0.1)\end{array}$ & $\begin{array}{c}0.00 \\
(1.0 \pm 0.0)\end{array}$ & $\begin{array}{c}8.33 \\
(16.8 \pm 0.0)\end{array}$ & $\begin{array}{c}0.00 \\
(0.0 \pm 0.0)\end{array}$ \\
\hline 5.0 & 0.0 & 2.0 & $\begin{array}{c}53.09 \\
(46.8 \pm 0.7) \\
\end{array}$ & $\begin{array}{c}13.58 \\
(21.6 \pm 1.1) \\
\end{array}$ & $\begin{array}{c}2.33 \\
(1.8 \pm 0.0) \\
\end{array}$ & $\begin{array}{c}0.44 \\
(1.2 \pm 0.1) \\
\end{array}$ & $\begin{array}{c}57.78 \\
(49.5 \pm 0.7) \\
\end{array}$ & $\begin{array}{c}50.00 \\
(44.9 \pm 0.0) \\
\end{array}$ & $\begin{array}{c}46.91 \\
(43.2 \pm 0.7) \\
\end{array}$ & $\begin{array}{c}20.99 \\
(27.2 \pm 0.9) \\
\end{array}$ & $\begin{array}{c}1.56 \\
(1.6 \pm 0.0) \\
\end{array}$ & $\begin{array}{c}0.33 \\
(1.2 \pm 0.0) \\
\end{array}$ & $\begin{array}{c}50.00 \\
(45.0 \pm 1.1) \\
\end{array}$ & $\begin{array}{c}42.59 \\
(40.7 \pm 1.1) \\
\end{array}$ \\
\hline 7.5 & 0.0 & 0.0 & $\begin{array}{c}86.42 \\
(68.4 \pm 1.1) \\
\end{array}$ & $\begin{array}{c}37.04 \\
(37.5 \pm 0.0)\end{array}$ & $\begin{array}{c}2.11 \\
(1.8 \pm 0.0)\end{array}$ & $\begin{array}{c}0.89 \\
(1.4 \pm 0.0) \\
\end{array}$ & $\begin{array}{c}55.75 \\
(48.3 \pm 0.5)\end{array}$ & $\begin{array}{c}46.30 \\
(42.8 \pm 2.1) \\
\end{array}$ & $\begin{array}{c}82.72 \\
(65.4 \pm 1.0) \\
\end{array}$ & $\begin{array}{c}38.27 \\
(38.2 \pm 0.7)\end{array}$ & $\begin{array}{c}1.22 \\
(1.5 \pm 0.0)\end{array}$ & $\begin{array}{c}0.89 \\
(1.4 \pm 0.0) \\
\end{array}$ & $\begin{array}{c}47.62 \\
(43.6 \pm 0.8) \\
\end{array}$ & $\begin{array}{c}40.74 \\
(39.6 \pm 1.1) \\
\end{array}$ \\
\hline 7.5 & 0.2 & 0.0 & $\begin{array}{c}61.73 \\
(51.8 \pm 0.7)\end{array}$ & $\begin{array}{c}12.35 \\
(20.5 \pm 1.1)\end{array}$ & $\begin{array}{c}1.00 \\
(1.4 \pm 0.1)\end{array}$ & $\begin{array}{c}0.33 \\
(1.2 \pm 0.0)\end{array}$ & $\begin{array}{c}30.37 \\
(33.4 \pm 0.6)\end{array}$ & $\begin{array}{c}27.78 \\
(31.5 \pm 3.7)\end{array}$ & $\begin{array}{c}59.26 \\
(50.3 \pm 0.0)\end{array}$ & $\begin{array}{c}13.58 \\
(21.6 \pm 1.1)\end{array}$ & $\begin{array}{c}0.89 \\
(1.4 \pm 0.0)\end{array}$ & $\begin{array}{c}0.22 \\
(1.1 \pm 0.1)\end{array}$ & $\begin{array}{c}28.89 \\
(32.5 \pm 1.4)\end{array}$ & $\begin{array}{c}20.37 \\
(26.8 \pm 1.3)\end{array}$ \\
\hline 7.5 & 0.0 & 2.0 & $\begin{array}{c}87.65 \\
(69.5 \pm 1.1)\end{array}$ & $\begin{array}{c}37.04 \\
(37.5 \pm 0.0)\end{array}$ & $\begin{array}{c}3.78 \\
(2.2 \pm 0.0)\end{array}$ & $\begin{array}{c}1.67 \\
(1.6 \pm 0.0)\end{array}$ & $\begin{array}{c}73.21 \\
(58.8 \pm 0.8)\end{array}$ & $\begin{array}{c}62.96 \\
(52.5 \pm 1.1)\end{array}$ & $\begin{array}{c}83.95 \\
(66.4 \pm 1.0)\end{array}$ & $\begin{array}{c}39.51 \\
(38.9 \pm 0.7)\end{array}$ & $\begin{array}{c}2.67 \\
(1.9 \pm 0.0)\end{array}$ & $\begin{array}{c}1.56 \\
(1.6 \pm 0.0)\end{array}$ & $\begin{array}{c}66.47 \\
(54.6 \pm 0.6)\end{array}$ & $\begin{array}{c}62.96 \\
(52.5 \pm 0.6)\end{array}$ \\
\hline 10.0 & 0.0 & 0.0 & $\begin{array}{c}87.65 \\
(69.5 \pm 1.1)\end{array}$ & $\begin{array}{c}38.27 \\
(38.2 \pm 0.7)\end{array}$ & $\begin{array}{c}2.22 \\
(1.8 \pm 0.0)\end{array}$ & $\begin{array}{c}0.89 \\
(1.4 \pm 0.0)\end{array}$ & $\begin{array}{c}56.15 \\
(48.5 \pm 0.7)\end{array}$ & $\begin{array}{c}48.15 \\
(43.9 \pm 1.1)\end{array}$ & $\begin{array}{c}81.48 \\
(64.5 \pm 0.0)\end{array}$ & $\begin{array}{c}37.04 \\
(37.5 \pm 0.0)\end{array}$ & $\begin{array}{c}1.11 \\
(1.5 \pm 0.0)\end{array}$ & $\begin{array}{c}0.78 \\
(1.3 \pm 0.0)\end{array}$ & $\begin{array}{c}45.24 \\
(42.3 \pm 0.0)\end{array}$ & $\begin{array}{c}38.89 \\
(38.6 \pm 0.0)\end{array}$ \\
\hline 10.0 & 0.2 & 0.0 & $\begin{array}{c}61.73 \\
(51.8 \pm 0.7)\end{array}$ & $\begin{array}{c}12.35 \\
(20.5 \pm 1.1)\end{array}$ & $\begin{array}{c}1.22 \\
(1.5 \pm 0.0)\end{array}$ & $\begin{array}{c}0.44 \\
(1.2 \pm 0.1)\end{array}$ & $\begin{array}{c}31.48 \\
(34.1 \pm 0.6)\end{array}$ & $\begin{array}{c}27.78 \\
(31.5 \pm 3.7)\end{array}$ & $\begin{array}{c}58.02 \\
(49.6 \pm 0.7)\end{array}$ & $\begin{array}{c}12.35 \\
(20.5 \pm 1.1)\end{array}$ & $\begin{array}{c}0.89 \\
(1.4 \pm 0.0)\end{array}$ & $\begin{array}{c}0.22 \\
(1.1 \pm 0.1)\end{array}$ & $\begin{array}{c}29.63 \\
(33.0 \pm 0.9)\end{array}$ & $\begin{array}{c}20.37 \\
(26.8 \pm 1.3)\end{array}$ \\
\hline 10.0 & 0.0 & 2.0 & $\begin{array}{c}88.89 \\
(70.5 \pm 0.0)\end{array}$ & $\begin{array}{c}38.27 \\
(38.2 \pm 0.7)\end{array}$ & $\begin{array}{c}3.89 \\
(2.2 \pm 0.0)\end{array}$ & $\begin{array}{c}1.78 \\
(1.7 \pm 0.0)\end{array}$ & $\begin{array}{c}73.61 \\
(59.1 \pm 0.9)\end{array}$ & $\begin{array}{c}62.96 \\
(52.5 \pm 1.1)\end{array}$ & $\begin{array}{c}82.72 \\
(65.4 \pm 1.0)\end{array}$ & $\begin{array}{c}37.04 \\
(37.5 \pm 0.0)\end{array}$ & $\begin{array}{c}2.56 \\
(1.9 \pm 0.0)\end{array}$ & $\begin{array}{c}1.44 \\
(1.6 \pm 0.0)\end{array}$ & $\begin{array}{c}65.87 \\
(54.3 \pm 1.6)\end{array}$ & $\begin{array}{c}61.11 \\
(51.4 \pm 0.0)\end{array}$ \\
\hline \multicolumn{3}{|c|}{$\mathrm{CD}$ at $5 \%$} & 2.28 & 2.39 & 0.09 & 0.08 & 2.99 & 5.07 & 2.08 & 2.29 & 0.10 & 0.09 & 2.34 & 2.11 \\
\hline
\end{tabular}

*** Figures in parenthesis are angular and square root transformed values, respectively 
Table.3 Effect of MS medium with Kinetin \pm NAA/GA 3 on regeneration of cotyledon explants of Capsicum hybrids Bharat and Indra having abaxial as well as adaxial side in contact with the growing medium

\begin{tabular}{|c|c|c|c|c|c|c|c|c|c|c|c|c|c|c|}
\hline \multirow{2}{*}{\multicolumn{3}{|c|}{$\begin{array}{c}\text { MS + growth regulators } \\
(\mathrm{mg} / \mathrm{l})\end{array}$}} & \multicolumn{6}{|l|}{ Bharat } & \multicolumn{6}{|l|}{ Indra } \\
\hline & & & \multicolumn{2}{|c|}{ Per cent Regeneration } & \multicolumn{2}{|c|}{$\begin{array}{c}\text { Elongated shoots per } \\
\text { explant }\end{array}$} & \multicolumn{2}{|c|}{ Per cent shoot elongation } & \multicolumn{2}{|c|}{ Per cent Regeneration } & \multicolumn{2}{|c|}{$\begin{array}{c}\text { Elongated shoots per } \\
\text { explant }\end{array}$} & \multicolumn{2}{|c|}{$\begin{array}{c}\text { Per cent shoot } \\
\text { elongation }\end{array}$} \\
\hline Kinetin & NAA & $\mathbf{G A}_{3}$ & abaxial & adaxial & abaxial & adaxial & abaxial & adaxial & abaxial & adaxial & abaxial & adaxial & abaxial & adaxial \\
\hline 2.5 & 0.0 & 0.0 & $\begin{array}{c}29.63 \\
(33.3 \pm 0.0) \\
\end{array}$ & $\begin{array}{c}0.00 \\
(0.0 \pm 0.0)\end{array}$ & $\begin{array}{c}0.00 \\
(1.0 \pm 0.0)\end{array}$ & $\begin{array}{c}0.00 \\
(1.0 \pm 0.0)\end{array}$ & $\begin{array}{c}0.00 \\
(0.0 \pm 0.0)\end{array}$ & $\begin{array}{c}0.00 \\
(0.0 \pm 0.0)\end{array}$ & $\begin{array}{c}35.80 \\
(36.7 \pm 0.7) \\
\end{array}$ & $\begin{array}{c}0.00 \\
(0.0 \pm 0.0)\end{array}$ & $\begin{array}{c}0.00 \\
(1.0 \pm 0.0)\end{array}$ & $\begin{array}{c}0.00 \\
(1.0 \pm 0.0)\end{array}$ & $\begin{array}{c}0.00 \\
(0.0 \pm 0.0)\end{array}$ & $\begin{array}{c}0.00 \\
(0.0 \pm 0.0)\end{array}$ \\
\hline 2.5 & 0.2 & 0.0 & $\begin{array}{c}16.05 \\
(23.6 \pm 1.0)\end{array}$ & $\begin{array}{c}0.00 \\
(0.0 \pm 0.0)\end{array}$ & $\begin{array}{c}0.00 \\
(1.0 \pm 0.0)\end{array}$ & $\begin{array}{c}0.00 \\
(1.0 \pm 0.0)\end{array}$ & $\begin{array}{c}0.00 \\
(0.0 \pm 0.0)\end{array}$ & $\begin{array}{c}0.00 \\
(0.0 \pm 0.0)\end{array}$ & $\begin{array}{c}14.81 \\
(22.6 \pm 0.0)\end{array}$ & $\begin{array}{c}0.00 \\
(0.0 \pm 0.0)\end{array}$ & $\begin{array}{c}0.00 \\
(1.0 \pm 0.0)\end{array}$ & $\begin{array}{c}0.00 \\
(1.0 \pm 0.0)\end{array}$ & $\begin{array}{c}0.00 \\
(0.0 \pm 0.0)\end{array}$ & $\begin{array}{c}0.00 \\
(0.0 \pm 0.0)\end{array}$ \\
\hline 2.5 & 0.0 & 2.0 & $\begin{array}{c}30.86 \\
(33.7 \pm 0.8)\end{array}$ & $\begin{array}{c}0.00 \\
(0.0 \pm 0.0)\end{array}$ & $\begin{array}{c}0.89 \\
(1.4 \pm 0.0) \\
\end{array}$ & $\begin{array}{c}0.00 \\
(1.0 \pm 0.0)\end{array}$ & $\begin{array}{c}22.22 \\
(28.1 \pm 0.0)\end{array}$ & $\begin{array}{c}0.00 \\
(0.0 \pm 0.0)\end{array}$ & $\begin{array}{c}35.80 \\
(36.7 \pm 0.7)\end{array}$ & $\begin{array}{c}0.00 \\
(0.0 \pm 0.0)\end{array}$ & $\begin{array}{c}1.00 \\
(1.4 \pm 0.0)\end{array}$ & $\begin{array}{c}0.00 \\
(1.0 \pm 0.0)\end{array}$ & $\begin{array}{c}22.22 \\
(28.1 \pm 0.0)\end{array}$ & $\begin{array}{c}0.00 \\
(0.0 \pm 0.0) \\
\end{array}$ \\
\hline 5.0 & 0.0 & 0.0 & $\begin{array}{c}53.09 \\
(46.8 \pm 0.7) \\
\end{array}$ & $\begin{array}{c}14.81 \\
(22.6 \pm 0.0)\end{array}$ & $\begin{array}{c}1.00 \\
(1.4 \pm 0.1)\end{array}$ & $\begin{array}{c}0.22 \\
(1.1 \pm 0.1)\end{array}$ & $\begin{array}{c}36.67 \\
(37.2 \pm 1.0) \\
\end{array}$ & $\begin{array}{c}27.78 \\
(31.5 \pm 3.7) \\
\end{array}$ & $\begin{array}{c}58.02 \\
(49.6 \pm 0.7) \\
\end{array}$ & $\begin{array}{c}23.46 \\
(28.9 \pm 0.8) \\
\end{array}$ & $\begin{array}{c}1.11 \\
(1.5 \pm 0.0)\end{array}$ & $\begin{array}{c}0.44 \\
(1.2 \pm 0.1) \\
\end{array}$ & $\begin{array}{c}40.37 \\
(39.4 \pm 0.0) \\
\end{array}$ & $\begin{array}{c}33.33 \\
(35.3 \pm 0.0) \\
\end{array}$ \\
\hline 5.0 & 0.2 & 0.0 & $\begin{array}{c}39.51 \\
(38.9 \pm 0.7) \\
\end{array}$ & $\begin{array}{c}8.64 \\
(17.0 \pm 1.2) \\
\end{array}$ & $\begin{array}{c}0.78 \\
(1.3 \pm 0.0) \\
\end{array}$ & $\begin{array}{c}0.00 \\
(1.0 \pm 0.0)\end{array}$ & $\begin{array}{c}16.67 \\
(24.1 \pm 0.0) \\
\end{array}$ & $\begin{array}{c}0.00 \\
(0.0 \pm 0.0)\end{array}$ & $\begin{array}{c}39.51 \\
(38.9 \pm 0.7) \\
\end{array}$ & $\begin{array}{c}11.11 \\
(19.5 \pm 0.0) \\
\end{array}$ & $\begin{array}{c}0.78 \\
(1.3 \pm 0.0) \\
\end{array}$ & $\begin{array}{c}0.00 \\
(1.0 \pm 0.0) \\
\end{array}$ & $\begin{array}{c}20.37 \\
(26.8 \pm 0.7) \\
\end{array}$ & $\begin{array}{c}0.00 \\
(0.0 \pm 0.0)\end{array}$ \\
\hline 5.0 & 0.0 & 2.0 & $\begin{array}{c}54.32 \\
(47.5 \pm 0.7)\end{array}$ & $\begin{array}{c}14.81 \\
(22.6 \pm 0.0)\end{array}$ & $\begin{array}{c}2.56 \\
(1.9 \pm 0.1)\end{array}$ & $\begin{array}{c}0.67 \\
(1.3 \pm 0.0)\end{array}$ & $\begin{array}{c}58.89 \\
(50.1 \pm 0.7)\end{array}$ & $\begin{array}{c}50.00 \\
(45.0 \pm 0.0)\end{array}$ & $\begin{array}{c}59.26 \\
(50.3 \pm 0.0)\end{array}$ & $\begin{array}{c}24.69 \\
(29.8 \pm 0.8)\end{array}$ & $\begin{array}{c}2.78 \\
(1.9 \pm 0.0)\end{array}$ & $\begin{array}{c}0.78 \\
(1.3 \pm 0.0)\end{array}$ & $\begin{array}{c}60.37 \\
(51.0 \pm 1.1)\end{array}$ & $\begin{array}{c}51.85 \\
(46.1 \pm 1.1)\end{array}$ \\
\hline 7.5 & 0.0 & 0.0 & $\begin{array}{c}90.12 \\
(71.7 \pm 1.2)\end{array}$ & $\begin{array}{c}38.27 \\
(38.2 \pm 1.5) \\
\end{array}$ & $\begin{array}{c}2.78 \\
(1.9 \pm 0.0) \\
\end{array}$ & $\begin{array}{c}1.11 \\
(1.5 \pm 0.0) \\
\end{array}$ & $\begin{array}{c}57.56 \\
(49.3 \pm 0.5) \\
\end{array}$ & $\begin{array}{c}48.15 \\
(43.9 \pm 2.1) \\
\end{array}$ & $\begin{array}{c}91.36 \\
(73.0 \pm 1.2) \\
\end{array}$ & $\begin{array}{c}41.98 \\
(40.4 \pm 0.7) \\
\end{array}$ & $\begin{array}{c}2.89 \\
(2.0 \pm 0.1) \\
\end{array}$ & $\begin{array}{c}1.22 \\
(1.5 \pm 0.0) \\
\end{array}$ & $\begin{array}{c}58.18 \\
(49.7 \pm 1.3) \\
\end{array}$ & $\begin{array}{c}50.00 \\
(45.0 \pm 1.8) \\
\end{array}$ \\
\hline 7.5 & 0.2 & 0.0 & $\begin{array}{c}62.96 \\
(52.5 \pm 0.0)\end{array}$ & $\begin{array}{c}13.58 \\
(21.6 \pm 1.1) \\
\end{array}$ & $\begin{array}{c}1.33 \\
(1.5 \pm 0.0) \\
\end{array}$ & $\begin{array}{c}0.67 \\
(1.3 \pm 0.0)\end{array}$ & $\begin{array}{c}33.33 \\
(35.2 \pm 1.4) \\
\end{array}$ & $\begin{array}{c}27.78 \\
(31.5 \pm 3.7) \\
\end{array}$ & $\begin{array}{c}64.20 \\
(53.2 \pm 0.7) \\
\end{array}$ & $\begin{array}{c}18.52 \\
(25.4 \pm 1.6)\end{array}$ & $\begin{array}{c}1.44 \\
(1.6 \pm 0.0) \\
\end{array}$ & $\begin{array}{c}0.78 \\
(1.3 \pm 0.0) \\
\end{array}$ & $\begin{array}{c}38.52 \\
(38.3 \pm 1.0) \\
\end{array}$ & $\begin{array}{c}27.78 \\
(31.8 \pm 0.0) \\
\end{array}$ \\
\hline 7.5 & 0.0 & 2.0 & $\begin{array}{c}91.36 \\
(73.0 \pm 1.2)\end{array}$ & $\begin{array}{c}38.27 \\
(38.2 \pm 1.5) \\
\end{array}$ & $\begin{array}{c}3.89 \\
(2.2 \pm 0.0) \\
\end{array}$ & $\begin{array}{c}1.78 \\
(1.7 \pm 0.0)\end{array}$ & $\begin{array}{c}75.62 \\
(60.4 \pm 0.2)\end{array}$ & $\begin{array}{c}64.81 \\
(53.6 \pm 0.6) \\
\end{array}$ & $\begin{array}{c}92.59 \\
(74.5 \pm 2.4)\end{array}$ & $\begin{array}{c}43.21 \\
(41.1 \pm 0.7) \\
\end{array}$ & $\begin{array}{c}4.11 \\
(2.3 \pm 0.0) \\
\end{array}$ & $\begin{array}{c}2.00 \\
(1.7 \pm 0.1) \\
\end{array}$ & $\begin{array}{c}76.08 \\
(60.7 \pm 1.2) \\
\end{array}$ & $\begin{array}{c}65.93 \\
(54.3 \pm 0.6) \\
\end{array}$ \\
\hline 10.0 & 0.0 & 0.0 & $\begin{array}{c}90.12 \\
(71.7 \pm 1.2)\end{array}$ & $\begin{array}{c}39.51 \\
(38.9 \pm 0.7) \\
\end{array}$ & $\begin{array}{c}2.89 \\
(2.0 \pm 0.0) \\
\end{array}$ & $\begin{array}{c}1.22 \\
(1.5 \pm 0.0)\end{array}$ & $\begin{array}{c}57.56 \\
(49.3 \pm 0.5) \\
\end{array}$ & $\begin{array}{c}50.00 \\
(45.0 \pm 1.8) \\
\end{array}$ & $\begin{array}{c}91.36 \\
(73.0 \pm 1.2) \\
\end{array}$ & $\begin{array}{c}40.74 \\
(39.7 \pm 0.0) \\
\end{array}$ & $\begin{array}{c}2.78 \\
(1.9 \pm 0.0) \\
\end{array}$ & $\begin{array}{c}1.22 \\
(1.5 \pm 0.0) \\
\end{array}$ & $\begin{array}{c}56.79 \\
(48.9 \pm 0.5) \\
\end{array}$ & $\begin{array}{c}48.15 \\
(43.9 \pm 2.3) \\
\end{array}$ \\
\hline 10.0 & 0.2 & 0.0 & $\begin{array}{c}62.96 \\
(52.5 \pm 0.0)\end{array}$ & $\begin{array}{c}14.81 \\
(22.6 \pm 0.0)\end{array}$ & $\begin{array}{c}1.44 \\
(1.6 \pm 0.0)\end{array}$ & $\begin{array}{c}0.78 \\
(1.3 \pm 0.0)\end{array}$ & $\begin{array}{c}33.33 \\
(35.2 \pm 1.4)\end{array}$ & $\begin{array}{c}27.78 \\
(31.5 \pm 3.7)\end{array}$ & $\begin{array}{c}62.96 \\
(52.5 \pm 0.0)\end{array}$ & $\begin{array}{c}18.52 \\
(25.4 \pm 1.6)\end{array}$ & $\begin{array}{c}1.33 \\
(1.5 \pm 0.0)\end{array}$ & $\begin{array}{c}0.78 \\
(1.3 \pm 0.0)\end{array}$ & $\begin{array}{c}37.41 \\
(37.7 \pm 1.1)\end{array}$ & $\begin{array}{c}27.78 \\
(31.8 \pm 0.0)\end{array}$ \\
\hline 10.0 & 0.0 & 2.0 & $\begin{array}{c}91.36 \\
(73.0 \pm 1.2)\end{array}$ & $\begin{array}{c}40.74 \\
(39.7 \pm 0.0)\end{array}$ & $\begin{array}{c}4.00 \\
(2.2 \pm 0.0)\end{array}$ & $\begin{array}{c}1.89 \\
(1.7 \pm 0.0)\end{array}$ & $\begin{array}{c}75.77 \\
(60.5 \pm 0.3)\end{array}$ & $\begin{array}{c}65.00 \\
(53.7 \pm 0.7)\end{array}$ & $\begin{array}{c}91.36 \\
(73.0 \pm 1.2)\end{array}$ & $\begin{array}{c}41.98 \\
(40.4 \pm 0.7)\end{array}$ & $\begin{array}{c}4.00 \\
(2.2 \pm 0.0)\end{array}$ & $\begin{array}{c}2.00 \\
(1.7 \pm 0.0)\end{array}$ & $\begin{array}{c}75.93 \\
(60.6 \pm 1.3)\end{array}$ & $\begin{array}{c}64.81 \\
(53.6 \pm 0.6)\end{array}$ \\
\hline \multicolumn{3}{|c|}{$\mathrm{CD}$ at $5 \%$} & 2.55 & 2.37 & 0.11 & 0.08 & 2.01 & 6.01 & 3.06 & 2.39 & 0.09 & 0.10 & 2.59 & 2.65 \\
\hline
\end{tabular}

$*, * *$ Figures in parenthesis are angular and square root transformed values, respectively 
Table.4 Effect of MS medium with TDZ \pm NAA/GA 3 on regeneration of cotyledon explants of Capsicum hybrids Bharat and Indra having abaxial as well as adaxial side in contact with the growing medium

\begin{tabular}{|c|c|c|c|c|c|c|c|c|c|c|c|c|c|c|}
\hline \multirow{2}{*}{\multicolumn{3}{|c|}{$\underset{(\mathrm{mg} / \mathrm{l})}{\mathrm{MS}+\text { growth regulators }^{-}}$}} & \multicolumn{6}{|l|}{ Bharat } & \multicolumn{6}{|l|}{ Indra } \\
\hline & & & \multicolumn{2}{|c|}{ Per cent Regeneration } & \multicolumn{2}{|c|}{$\begin{array}{c}\text { Elongated shoots per } \\
\text { explant }\end{array}$} & \multicolumn{2}{|c|}{ Per cent shoot elongation } & \multicolumn{2}{|c|}{ Per cent Regeneration } & \multicolumn{2}{|c|}{$\begin{array}{c}\text { Elongated shoots per } \\
\text { explant }\end{array}$} & \multicolumn{2}{|c|}{$\begin{array}{c}\text { Per cent shoot } \\
\text { elongation }\end{array}$} \\
\hline TDZ & NAA & $\mathbf{G A}_{3}$ & abaxial & adaxial & abaxial & adaxial & abaxial & adaxial & abaxial & adaxial & abaxial & adaxial & abaxial & adaxial \\
\hline 2.5 & 0.0 & 0.0 & $\begin{array}{c}62.96 \\
(52.5 \pm 0.0) \\
\end{array}$ & $\begin{array}{c}8.64 \\
(17.0 \pm 1.2) \\
\end{array}$ & $\begin{array}{c}0.56 \\
(1.3 \pm 0.1)\end{array}$ & $\begin{array}{c}0.00 \\
(1.0 \pm 0.0)\end{array}$ & $\begin{array}{c}23.33 \\
(28.9 \pm 0.0) \\
\end{array}$ & $\begin{array}{c}0.00 \\
(0.0 \pm 0.0) \\
\end{array}$ & $\begin{array}{c}58.02 \\
(49.6 \pm 0.7)\end{array}$ & $\begin{array}{c}12.35 \\
(20.5 \pm 1.1)\end{array}$ & $\begin{array}{c}0.33 \\
(1.2 \pm 0.0)\end{array}$ & $\begin{array}{c}0.00 \\
(1.0 \pm 0.0)\end{array}$ & $\begin{array}{c}19.26 \\
(26.0 \pm 0.3) \\
\end{array}$ & $\begin{array}{c}0.00 \\
(0.0 \pm 0.0)\end{array}$ \\
\hline 2.5 & 0.2 & 0.0 & $\begin{array}{c}39.51 \\
(38.9 \pm 0.7)\end{array}$ & $\begin{array}{c}3.70 \\
(11.1 \pm 0.0)\end{array}$ & $\begin{array}{c}0.00 \\
(1.0 \pm 0.0)\end{array}$ & $\begin{array}{c}0.00 \\
(1.0 \pm 0.0)\end{array}$ & $\begin{array}{c}0.00 \\
(0.0 \pm 0.0)\end{array}$ & $\begin{array}{c}0.00 \\
(0.0 \pm 0.0)\end{array}$ & $\begin{array}{c}35.80 \\
(36.7 \pm 0.7)\end{array}$ & $\begin{array}{c}0.00 \\
(0.0 \pm 0.0)\end{array}$ & $\begin{array}{c}0.00 \\
(1.0 \pm 0.0)\end{array}$ & $\begin{array}{c}0.00 \\
(1.0 \pm 0.0)\end{array}$ & $\begin{array}{c}0.00 \\
(0.0 \pm 0.0)\end{array}$ & $\begin{array}{c}0.00 \\
(0.0 \pm 0.0)\end{array}$ \\
\hline 2.5 & 0.0 & 2.0 & $\begin{array}{c}64.20 \\
(53.2 \pm 0.7)\end{array}$ & $\begin{array}{c}8.64 \\
(17.0 \pm 1.2)\end{array}$ & $\begin{array}{c}1.78 \\
(1.7 \pm 0.0)\end{array}$ & $\begin{array}{c}0.44 \\
(1.2 \pm 0.1)\end{array}$ & $\begin{array}{c}40.37 \\
(39.4 \pm 0.4)\end{array}$ & $\begin{array}{c}33.33 \\
(35.3 \pm 0.0)\end{array}$ & $\begin{array}{c}59.26 \\
(50.3 \pm 0.0)\end{array}$ & $\begin{array}{c}13.58 \\
(21.6 \pm 1.1)\end{array}$ & $\begin{array}{c}1.44 \\
(1.6 \pm 0.0)\end{array}$ & $\begin{array}{c}0.33 \\
(1.2 \pm 0.0)\end{array}$ & $\begin{array}{c}37.78 \\
(37.9 \pm 0.0)\end{array}$ & $\begin{array}{c}33.33 \\
(35.3 \pm 0.0)\end{array}$ \\
\hline 5.0 & 0.0 & 0.0 & $\begin{array}{c}91.36 \\
(73.0 \pm 1.2) \\
\end{array}$ & $\begin{array}{c}37.04 \\
(37.5 \pm 0.0) \\
\end{array}$ & $\begin{array}{c}0.89 \\
(1.4 \pm 0.0)\end{array}$ & $\begin{array}{c}0.33 \\
(1.2 \pm 0.0) \\
\end{array}$ & $\begin{array}{c}31.02 \\
(33.8 \pm 0.6)\end{array}$ & $\begin{array}{c}27.78 \\
(28.6 \pm 0.0) \\
\end{array}$ & $\begin{array}{c}83.95 \\
(66.4 \pm 1.0) \\
\end{array}$ & $\begin{array}{c}39.51 \\
(38.9 \pm 0.7) \\
\end{array}$ & $\begin{array}{c}0.78 \\
(1.3 \pm 0.0) \\
\end{array}$ & $\begin{array}{c}0.22 \\
(1.1 \pm 0.1)\end{array}$ & $\begin{array}{c}30.75 \\
(33.7 \pm 0.3) \\
\end{array}$ & $\begin{array}{c}27.78 \\
(31.8 \pm 0.0) \\
\end{array}$ \\
\hline 5.0 & 0.2 & 0.0 & $\begin{array}{c}59.26 \\
(50.3 \pm 1.3) \\
\end{array}$ & $\begin{array}{c}13.58 \\
(21.6 \pm 1.1) \\
\end{array}$ & $\begin{array}{c}0.56 \\
(1.3 \pm 0.1)\end{array}$ & $\begin{array}{c}0.00 \\
(1.0 \pm 0.0)\end{array}$ & $\begin{array}{c}18.89 \\
(25.8 \pm 0.5)\end{array}$ & $\begin{array}{c}0.00 \\
(0.0 \pm 0.0)\end{array}$ & $\begin{array}{c}56.79 \\
(48.9 \pm 0.7)\end{array}$ & $\begin{array}{c}13.58 \\
(21.6 \pm 1.1)\end{array}$ & $\begin{array}{c}0.44 \\
(1.2 \pm 0.1)\end{array}$ & $\begin{array}{c}0.00 \\
(1.0 \pm 0.0)\end{array}$ & $\begin{array}{c}19.63 \\
(26.3 \pm 0.3)\end{array}$ & $\begin{array}{c}0.00 \\
(0.0 \pm 0.0)\end{array}$ \\
\hline 5.0 & 0.0 & 2.0 & $\begin{array}{c}92.59 \\
(74.2 \pm 0.0)\end{array}$ & $\begin{array}{c}37.04 \\
(37.5 \pm 0.0)\end{array}$ & $\begin{array}{c}2.44 \\
(1.9 \pm 0.0)\end{array}$ & $\begin{array}{c}1.11 \\
(1.5 \pm 0.1)\end{array}$ & $\begin{array}{c}57.41 \\
(49.3 \pm 0.8)\end{array}$ & $\begin{array}{c}50.00 \\
(45.0 \pm 0.0)\end{array}$ & $\begin{array}{c}85.19 \\
(67.4 \pm 1.7)\end{array}$ & $\begin{array}{c}40.74 \\
(39.7 \pm 0.0)\end{array}$ & $\begin{array}{c}1.89 \\
(1.7 \pm 0.0)\end{array}$ & $\begin{array}{c}1.00 \\
(1.4 \pm 0.0)\end{array}$ & $\begin{array}{c}55.16 \\
(47.9 \pm 0.4)\end{array}$ & $\begin{array}{c}49.07 \\
(44.5 \pm 1.9)\end{array}$ \\
\hline 7.5 & 0.0 & 0.0 & $\begin{array}{c}51.85 \\
(46.1 \pm 1.2) \\
\end{array}$ & $\begin{array}{c}9.88 \\
(18.2 \pm 1.2) \\
\end{array}$ & $\begin{array}{c}0.56 \\
(1.3 \pm 0.1) \\
\end{array}$ & $\begin{array}{c}0.00 \\
(1.0 \pm 0.0) \\
\end{array}$ & $\begin{array}{c}21.67 \\
(27.7 \pm 0.7) \\
\end{array}$ & $\begin{array}{c}0.00 \\
(0.0 \pm 0.0)\end{array}$ & $\begin{array}{c}39.51 \\
(38.9 \pm 0.7) \\
\end{array}$ & $\begin{array}{c}8.64 \\
(17.0 \pm 1.2) \\
\end{array}$ & $\begin{array}{c}0.44 \\
(1.2 \pm 0.1) \\
\end{array}$ & $\begin{array}{c}0.00 \\
(1.0 \pm 0.0) \\
\end{array}$ & $\begin{array}{c}17.59 \\
(24.8 \pm 0.7) \\
\end{array}$ & $\begin{array}{c}0.00 \\
(0.0 \pm 0.0) \\
\end{array}$ \\
\hline 7.5 & 0.2 & 0.0 & $\begin{array}{c}35.80 \\
(36.7 \pm 0.7)\end{array}$ & $\begin{array}{c}3.70 \\
(11.1 \pm 0.0)\end{array}$ & $\begin{array}{c}0.00 \\
(1.0 \pm 0.0)\end{array}$ & $\begin{array}{c}0.00 \\
(1.0 \pm 0.0)\end{array}$ & $\begin{array}{c}0.00 \\
(0.0 \pm 0.0)\end{array}$ & $\begin{array}{c}0.00 \\
(0.0 \pm 0.0)\end{array}$ & $\begin{array}{c}28.40 \\
(32.2 \pm 0.8)\end{array}$ & $\begin{array}{c}3.70 \\
(11.1 \pm 0.0)\end{array}$ & $\begin{array}{c}0.00 \\
(1.0 \pm 0.0)\end{array}$ & $\begin{array}{c}0.00 \\
(1.0 \pm 0.0)\end{array}$ & $\begin{array}{c}0.00 \\
(0.0 \pm 0.0)\end{array}$ & $\begin{array}{c}0.00 \\
(0.0 \pm 0.0)\end{array}$ \\
\hline 7.5 & 0.0 & 2.0 & $\begin{array}{c}53.09 \\
(46.8 \pm 0.7) \\
\end{array}$ & $\begin{array}{c}11.11 \\
(19.5 \pm 0.0)\end{array}$ & $\begin{array}{c}1.33 \\
(1.5 \pm 0.1) \\
\end{array}$ & $\begin{array}{c}0.00 \\
(1.0 \pm 0.0) \\
\end{array}$ & $\begin{array}{c}34.44 \\
(35.9 \pm 0.3)\end{array}$ & $\begin{array}{c}0.00 \\
(0.0 \pm 0.0)\end{array}$ & $\begin{array}{c}40.74 \\
(39.7 \pm 0.0)\end{array}$ & $\begin{array}{c}9.88 \\
(18.2 \pm 1.2)\end{array}$ & $\begin{array}{c}1.00 \\
(1.4 \pm 0.0) \\
\end{array}$ & $\begin{array}{c}0.00 \\
(1.0 \pm 0.0)\end{array}$ & $\begin{array}{c}27.78 \\
(31.8 \pm 0.0) \\
\end{array}$ & $\begin{array}{c}0.00 \\
(0.0 \pm 0.0)\end{array}$ \\
\hline 10.0 & 0.0 & 0.0 & $\begin{array}{c}8.64 \\
(17.0 \pm 1.2)\end{array}$ & $\begin{array}{c}0.00 \\
(0.0 \pm 0.0)\end{array}$ & $\begin{array}{c}0.00 \\
(1.0 \pm 0.0) \\
\end{array}$ & $\begin{array}{c}0.00 \\
(1.0 \pm 0.0) \\
\end{array}$ & $\begin{array}{c}0.00 \\
(0.0 \pm 0.0)\end{array}$ & $\begin{array}{c}0.00 \\
(0.0 \pm 0.0)\end{array}$ & $\begin{array}{c}0.00 \\
(0.0 \pm 0.0) \\
\end{array}$ & $\begin{array}{c}0.00 \\
(0.0 \pm 0.0) \\
\end{array}$ & $\begin{array}{c}0.00 \\
(1.0 \pm 0.0) \\
\end{array}$ & $\begin{array}{c}0.00 \\
(1.0 \pm 0.0) \\
\end{array}$ & $\begin{array}{c}0.00 \\
(0.0 \pm 0.0) \\
\end{array}$ & $\begin{array}{c}0.00 \\
(0.0 \pm 0.0)\end{array}$ \\
\hline $\mathbf{1 0 . 0}$ & 0.2 & 0.0 & $\begin{array}{c}3.70 \\
(11.1 \pm 0.0)\end{array}$ & $\begin{array}{c}0.00 \\
(0.0 \pm 0.0)\end{array}$ & $\begin{array}{c}0.00 \\
(1.0 \pm 0.0)\end{array}$ & $\begin{array}{c}0.00 \\
(1.0 \pm 0.0)\end{array}$ & $\begin{array}{c}0.00 \\
(0.0 \pm 0.0)\end{array}$ & $\begin{array}{c}0.00 \\
(0.0 \pm 0.0)\end{array}$ & $\begin{array}{c}0.00 \\
(0.0 \pm 0.0)\end{array}$ & $\begin{array}{c}0.00 \\
(0.0 \pm 0.0)\end{array}$ & $\begin{array}{c}0.00 \\
(1.0 \pm 0.0)\end{array}$ & $\begin{array}{c}0.00 \\
(1.0 \pm 0.0)\end{array}$ & $\begin{array}{c}0.00 \\
(0.0 \pm 0.0)\end{array}$ & $\begin{array}{c}0.00 \\
(0.0 \pm 0.0)\end{array}$ \\
\hline 10.0 & 0.0 & 2.0 & $\begin{array}{c}8.64 \\
(16.7 \pm 2.8)\end{array}$ & $\begin{array}{c}0.00 \\
(0.0 \pm 0.0)\end{array}$ & $\begin{array}{c}0.00 \\
(1.0 \pm 0.0)\end{array}$ & $\begin{array}{c}0.00 \\
(1.0 \pm 0.0)\end{array}$ & $\begin{array}{c}0.00 \\
(0.0 \pm 0.0)\end{array}$ & $\begin{array}{c}0.00 \\
(0.0 \pm 0.0)\end{array}$ & $\begin{array}{c}0.00 \\
(0.0 \pm 0.0)\end{array}$ & $\begin{array}{c}0.00 \\
(0.0 \pm 0.0)\end{array}$ & $\begin{array}{c}0.00 \\
(1.0 \pm 0.0)\end{array}$ & $\begin{array}{c}0.00 \\
(1.0 \pm 0.0)\end{array}$ & $\begin{array}{c}0.00 \\
(0.0 \pm 0.0)\end{array}$ & $\begin{array}{c}0.00 \\
(0.0 \pm 0.0)\end{array}$ \\
\hline \multicolumn{3}{|c|}{$\mathrm{CD}$ at $5 \%$} & 3.39 & 2.01 & 0.10 & 0.05 & 1.18 & 3.15 & 2.19 & 2.22 & 0.08 & 0.04 & 0.78 & 1.63 \\
\hline
\end{tabular}


Table.5 Effect of MS medium with Zeatin \pm NAA/GA 3 on regeneration of cotyledon explants of Capsicum hybrids Bharat and Indra having abaxial as well as adaxial side in contact with the growing medium

\begin{tabular}{|c|c|c|c|c|c|c|c|c|c|c|c|c|c|c|}
\hline \multirow{2}{*}{\multicolumn{3}{|c|}{$\begin{array}{c}\text { MS + growth regulators } \\
(\mathrm{mg} / \mathrm{l})\end{array}$}} & \multicolumn{6}{|l|}{ Bharat } & \multicolumn{6}{|l|}{ Indra } \\
\hline & & & \multicolumn{2}{|c|}{ Per cent Regeneration } & \multicolumn{2}{|c|}{$\begin{array}{c}\text { Elongated shoots per } \\
\text { explant }\end{array}$} & \multicolumn{2}{|c|}{ Per cent shoot elongation } & \multicolumn{2}{|c|}{ Per cent Regeneration } & \multicolumn{2}{|c|}{$\begin{array}{c}\text { Elongated shoots per } \\
\text { explant }\end{array}$} & \multicolumn{2}{|c|}{$\begin{array}{l}\text { Per cent shoot } \\
\text { elongation }\end{array}$} \\
\hline Zeatin & NAA & $\mathbf{G A}_{3}$ & abaxial & adaxial & abaxial & adaxial & abaxial & adaxial & abaxial & adaxial & abaxial & adaxial & abaxial & adaxial \\
\hline 2.5 & 0.0 & 0.0 & $\begin{array}{c}30.86 \\
(33.7 \pm 0.8) \\
\end{array}$ & $\begin{array}{c}6.17 \\
(14.2 \pm 1.6) \\
\end{array}$ & $\begin{array}{c}0.33 \\
(1.2 \pm 0.1)\end{array}$ & $\begin{array}{c}0.00 \\
(1.0 \pm 0.0)\end{array}$ & $\begin{array}{c}11.11 \\
(19.5 \pm 0.0) \\
\end{array}$ & $\begin{array}{c}0.00 \\
(0.0 \pm 0.0)\end{array}$ & $\begin{array}{c}39.51 \\
(38.9 \pm 0.7)\end{array}$ & $\begin{array}{c}7.41 \\
(15.8 \pm 0.0)\end{array}$ & $\begin{array}{c}0.44 \\
(1.2 \pm 0.1)\end{array}$ & $\begin{array}{c}0.33 \\
(1.2 \pm 0.0)\end{array}$ & $\begin{array}{c}16.67 \\
(24.1 \pm 0.0)\end{array}$ & $\begin{array}{c}0.00 \\
(11.8 \pm 0.0)\end{array}$ \\
\hline 2.5 & 0.2 & 0.0 & $\begin{array}{c}17.28 \\
(24.5 \pm 1.0)\end{array}$ & $\begin{array}{c}0.00 \\
(0.0 \pm 0.0)\end{array}$ & $\begin{array}{c}0.00 \\
(1.0 \pm 0.0)\end{array}$ & $\begin{array}{c}0.00 \\
(1.0 \pm 0.0)\end{array}$ & $\begin{array}{c}0.00 \\
(0.0 \pm 0.0)\end{array}$ & $\begin{array}{c}0.00 \\
(0.0 \pm 0.0)\end{array}$ & $\begin{array}{c}24.69 \\
(29.8 \pm 0.8)\end{array}$ & $\begin{array}{c}0.00 \\
(0.0 \pm 0.0)\end{array}$ & $\begin{array}{c}0.00 \\
(1.0 \pm 0.0)\end{array}$ & $\begin{array}{c}0.00 \\
(1.0 \pm 0.0)\end{array}$ & $\begin{array}{c}0.00 \\
(0.0 \pm 0.0)\end{array}$ & $\begin{array}{c}0.00 \\
(0.0 \pm 0.0)\end{array}$ \\
\hline 2.5 & 0.0 & 2.0 & $\begin{array}{c}32.10 \\
(34.5 \pm 0.8)\end{array}$ & $\begin{array}{c}6.17 \\
(14.2 \pm 1.6) \\
\end{array}$ & $\begin{array}{c}1.00 \\
(1.4 \pm 0.0)\end{array}$ & $\begin{array}{c}0.22 \\
(1.1 \pm 0.1)\end{array}$ & $\begin{array}{c}25.00 \\
(29.9 \pm 1.8)\end{array}$ & $\begin{array}{c}22.22 \\
(27.8 \pm 3.7) \\
\end{array}$ & $\begin{array}{c}40.74 \\
(39.7 \pm 0.0)\end{array}$ & $\begin{array}{c}8.64 \\
(17.0 \pm 1.2)\end{array}$ & $\begin{array}{c}1.00 \\
(1.4 \pm 0.1)\end{array}$ & $\begin{array}{c}0.56 \\
(1.3 \pm 0.1)\end{array}$ & $\begin{array}{c}33.33 \\
(35.3 \pm 0.0)\end{array}$ & $\begin{array}{c}33.33 \\
(31.3 \pm 0.7)\end{array}$ \\
\hline 5.0 & 0.0 & 0.0 & $\begin{array}{c}58.02 \\
(49.6 \pm 0.7) \\
\end{array}$ & $\begin{array}{c}19.75 \\
(26.4 \pm 0.9) \\
\end{array}$ & $\begin{array}{c}1.44 \\
(1.6 \pm 0.0) \\
\end{array}$ & $\begin{array}{c}0.44 \\
(1.2 \pm 0.1) \\
\end{array}$ & $\begin{array}{c}38.52 \\
(38.4 \pm 0.4) \\
\end{array}$ & $\begin{array}{c}29.63 \\
(33.0 \pm 1.2) \\
\end{array}$ & $\begin{array}{c}61.73 \\
(51.8 \pm 0.7) \\
\end{array}$ & $\begin{array}{c}28.40 \\
(32.2 \pm 0.8)\end{array}$ & $\begin{array}{c}1.56 \\
(1.6 \pm 0.0)\end{array}$ & $\begin{array}{c}0.67 \\
(1.3 \pm 0.1)\end{array}$ & $\begin{array}{c}47.78 \\
(43.7 \pm 0.6) \\
\end{array}$ & $\begin{array}{c}31.48 \\
(36.4 \pm 1.1) \\
\end{array}$ \\
\hline 5.0 & 0.2 & 0.0 & $\begin{array}{c}39.51 \\
(38.9 \pm 0.7) \\
\end{array}$ & $\begin{array}{c}9.88 \\
(18.2 \pm 1.2) \\
\end{array}$ & $\begin{array}{c}0.89 \\
(1.4 \pm 0.0) \\
\end{array}$ & $\begin{array}{c}0.11 \\
(1.1 \pm 0.1) \\
\end{array}$ & $\begin{array}{c}24.44 \\
(29.6 \pm 0.4)\end{array}$ & $\begin{array}{c}16.67 \\
(24.1 \pm 0.0) \\
\end{array}$ & $\begin{array}{c}43.21 \\
(41.1 \pm 0.7) \\
\end{array}$ & $\begin{array}{c}12.35 \\
(20.5 \pm 1.1)\end{array}$ & $\begin{array}{c}1.00 \\
(1.4 \pm 0.0) \\
\end{array}$ & $\begin{array}{c}0.22 \\
(1.1 \pm 0.1) \\
\end{array}$ & $\begin{array}{c}25.93 \\
(30.6 \pm 0.6)\end{array}$ & $\begin{array}{c}16.67 \\
(26.7 \pm 2.6 \\
\end{array}$ \\
\hline 5.0 & 0.0 & 2.0 & $\begin{array}{c}59.26 \\
(50.3 \pm 0.0) \\
\end{array}$ & $\begin{array}{c}20.99 \\
(27.2 \pm 0.9) \\
\end{array}$ & $\begin{array}{c}2.78 \\
(1.9 \pm 0.0) \\
\end{array}$ & $\begin{array}{c}0.89 \\
(1.4 \pm 0.0) \\
\end{array}$ & $\begin{array}{c}62.22 \\
(52.1 \pm 0.1) \\
\end{array}$ & $\begin{array}{c}51.85 \\
(46.1 \pm 1.1) \\
\end{array}$ & $\begin{array}{c}61.73 \\
(51.8 \pm 0.7) \\
\end{array}$ & $\begin{array}{c}28.40 \\
(32.2 \pm 0.8)\end{array}$ & $\begin{array}{c}2.89 \\
(2.0 \pm 0.0)\end{array}$ & $\begin{array}{c}1.11 \\
(1.5 \pm 0.0) \\
\end{array}$ & $\begin{array}{c}63.70 \\
(52.9 \pm 0.4) \\
\end{array}$ & $\begin{array}{c}40.74 \\
(46.1 \pm 1.1) \\
\end{array}$ \\
\hline 7.5 & 0.0 & 0.0 & $\begin{array}{c}92.59 \\
(74.2 \pm 0.0)\end{array}$ & $\begin{array}{c}41.98 \\
(40.4 \pm 0.7) \\
\end{array}$ & $\begin{array}{c}2.89 \\
(2.0 \pm 0.0) \\
\end{array}$ & $\begin{array}{c}1.33 \\
(1.5 \pm 0.0) \\
\end{array}$ & $\begin{array}{c}58.80 \\
(50.1 \pm 0.8) \\
\end{array}$ & $\begin{array}{c}50.00 \\
(45.0 \pm 1.8) \\
\end{array}$ & $\begin{array}{c}95.06 \\
(77.3 \pm 1.6) \\
\end{array}$ & $\begin{array}{c}45.68 \\
(42.5 \pm 0.7)\end{array}$ & $\begin{array}{c}3.00 \\
(2.0 \pm 0.1)\end{array}$ & $\begin{array}{c}1.56 \\
(1.6 \pm 0.0) \\
\end{array}$ & $\begin{array}{c}59.88 \\
(50.7 \pm 0.6) \\
\end{array}$ & $\begin{array}{c}40.56 \\
(45.6 \pm 0.6 \\
\end{array}$ \\
\hline 7.5 & 0.2 & 0.0 & $\begin{array}{c}62.96 \\
(52.5 \pm 0.0)\end{array}$ & $\begin{array}{c}17.28 \\
(24.5 \pm 1.0) \\
\end{array}$ & $\begin{array}{c}1.56 \\
(1.6 \pm 0.0) \\
\end{array}$ & $\begin{array}{c}0.78 \\
(1.3 \pm 0.0)\end{array}$ & $\begin{array}{c}35.56 \\
(36.6 \pm 0.0) \\
\end{array}$ & $\begin{array}{c}33.33 \\
(35.3 \pm 0.0) \\
\end{array}$ & $\begin{array}{c}67.90 \\
(55.5 \pm 0.8)\end{array}$ & $\begin{array}{c}19.75 \\
(26.4 \pm 0.9)\end{array}$ & $\begin{array}{c}1.67 \\
(1.6 \pm 0.1) \\
\end{array}$ & $\begin{array}{c}1.00 \\
(1.4 \pm 0.0) \\
\end{array}$ & $\begin{array}{c}39.95 \\
(39.2 \pm 0.6) \\
\end{array}$ & $\begin{array}{c}33.33 \\
(36.4 \pm 1.1) \\
\end{array}$ \\
\hline 7.5 & 0.0 & 2.0 & $\begin{array}{c}93.83 \\
(75.7 \pm 1.6) \\
\end{array}$ & $\begin{array}{c}41.98 \\
(40.4 \pm 0.7) \\
\end{array}$ & $\begin{array}{c}4.44 \\
(2.3 \pm 0.0)\end{array}$ & $\begin{array}{c}1.89 \\
(1.7 \pm 0.0)\end{array}$ & $\begin{array}{c}80.40 \\
(63.7 \pm 0.2) \\
\end{array}$ & $\begin{array}{c}67.59 \\
(55.3 \pm 1.5) \\
\end{array}$ & $\begin{array}{c}96.30 \\
(78.9 \pm 0.0)\end{array}$ & $\begin{array}{c}46.91 \\
(43.2 \pm 0.7)\end{array}$ & $\begin{array}{c}4.56 \\
(2.4 \pm 0.0) \\
\end{array}$ & $\begin{array}{c}2.33 \\
(1.8 \pm 0.0) \\
\end{array}$ & $\begin{array}{c}82.10 \\
(65.0 \pm 1.0) \\
\end{array}$ & $\begin{array}{c}63.33 \\
(57.8 \pm 1.1) \\
\end{array}$ \\
\hline 10.0 & 0.0 & 0.0 & $\begin{array}{c}93.83 \\
(75.7 \pm 1.6)\end{array}$ & $\begin{array}{c}43.21 \\
(41.1 \pm 0.7)\end{array}$ & $\begin{array}{c}2.89 \\
(2.0 \pm 0.0)\end{array}$ & $\begin{array}{c}1.33 \\
(1.5 \pm 0.1)\end{array}$ & $\begin{array}{c}59.41 \\
(50.4 \pm 0.5)\end{array}$ & $\begin{array}{c}51.85 \\
(46.1 \pm 1.1)\end{array}$ & $\begin{array}{c}95.06 \\
(77.3 \pm 1.6)\end{array}$ & $\begin{array}{c}44.44 \\
(41.8 \pm 0.0)\end{array}$ & $\begin{array}{c}2.89 \\
(2.0 \pm 0.0)\end{array}$ & $\begin{array}{c}1.56 \\
(1.6 \pm 0.0)\end{array}$ & $\begin{array}{c}58.64 \\
(50.0 \pm 0.5)\end{array}$ & $\begin{array}{c}41.67 \\
(46.1 \pm 1.1)\end{array}$ \\
\hline 10.0 & 0.2 & 0.0 & $\begin{array}{c}62.96 \\
(52.5 \pm 0.0)\end{array}$ & $\begin{array}{c}18.52 \\
(25.5 \pm 0.0)\end{array}$ & $\begin{array}{c}1.78 \\
(1.7 \pm 0.0)\end{array}$ & $\begin{array}{c}0.89 \\
(1.4 \pm 0.0)\end{array}$ & $\begin{array}{c}35.56 \\
(36.6 \pm 0.0)\end{array}$ & $\begin{array}{c}33.33 \\
(35.3 \pm 0.0)\end{array}$ & $\begin{array}{c}64.20 \\
(53.2 \pm 0.7)\end{array}$ & $\begin{array}{c}19.75 \\
(26.4 \pm 0.9)\end{array}$ & $\begin{array}{c}1.56 \\
(1.6 \pm 0.0)\end{array}$ & $\begin{array}{c}1.00 \\
(1.4 \pm 0.0)\end{array}$ & $\begin{array}{c}38.52 \\
(38.3 \pm 1.0)\end{array}$ & $\begin{array}{c}33.33 \\
(36.4 \pm 1.1)\end{array}$ \\
\hline 10.0 & 0.0 & 2.0 & $\begin{array}{c}93.83 \\
(75.7 \pm 1.6)\end{array}$ & $\begin{array}{c}43.21 \\
(41.1 \pm 0.7)\end{array}$ & $\begin{array}{c}4.56 \\
(2.4 \pm 0.0)\end{array}$ & $\begin{array}{c}2.11 \\
(1.8 \pm 0.0)\end{array}$ & $\begin{array}{c}81.79 \\
(64.7 \pm 1.0)\end{array}$ & $\begin{array}{c}68.52 \\
(55.9 \pm 1.2)\end{array}$ & $\begin{array}{c}95.06 \\
(77.3 \pm 1.6)\end{array}$ & $\begin{array}{c}45.68 \\
(42.5 \pm 0.7)\end{array}$ & $\begin{array}{c}4.44 \\
(2.3 \pm 0.0)\end{array}$ & $\begin{array}{c}2.22 \\
(1.8 \pm 0.0)\end{array}$ & $\begin{array}{c}80.71 \\
(64.0 \pm 1.6)\end{array}$ & $\begin{array}{c}62.22 \\
(57.8 \pm 1.1\end{array}$ \\
\hline \multicolumn{3}{|l|}{$\mathrm{CD}$ at $5 \%$} & 2.74 & 2.80 & 0.11 & 0.12 & 1.97 & 4.19 & 2.85 & 2.23 & 0.11 & 0.11 & 2.12 & 2.64 \\
\hline
\end{tabular}

\footnotetext{
*,** Figures in parenthesis are angular and square root transformed values, respectively
} 

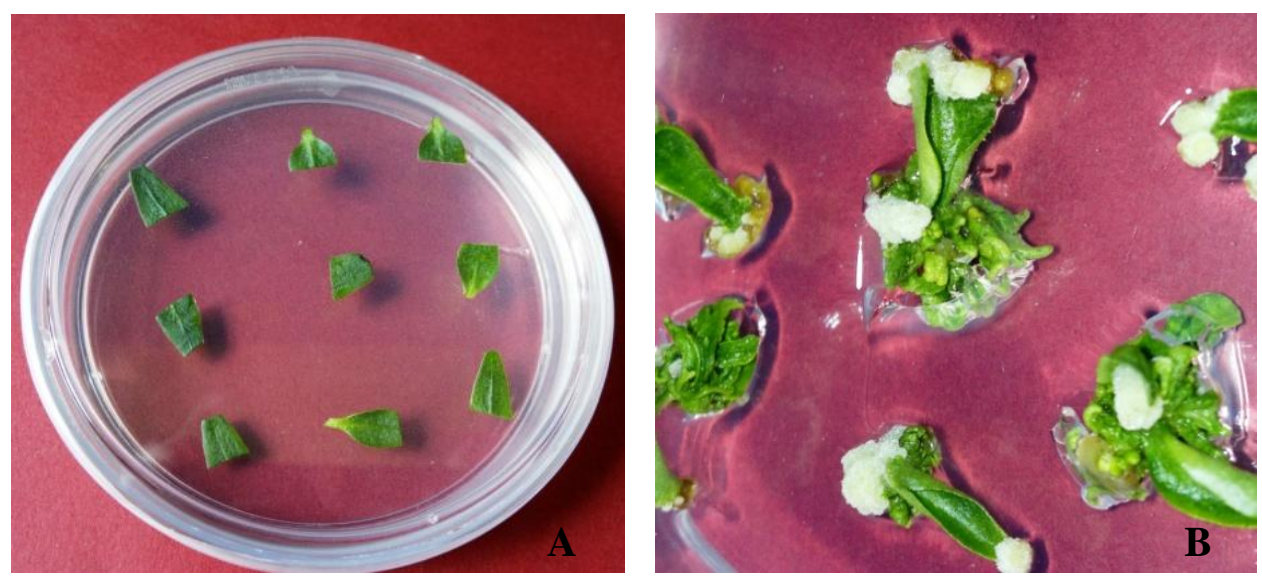

Plate.1 (A) Cotyledonary explants, adaxial side contact with regeneration medium, (B) Multiple shoots induction at the cut ends of cotyledonary explants
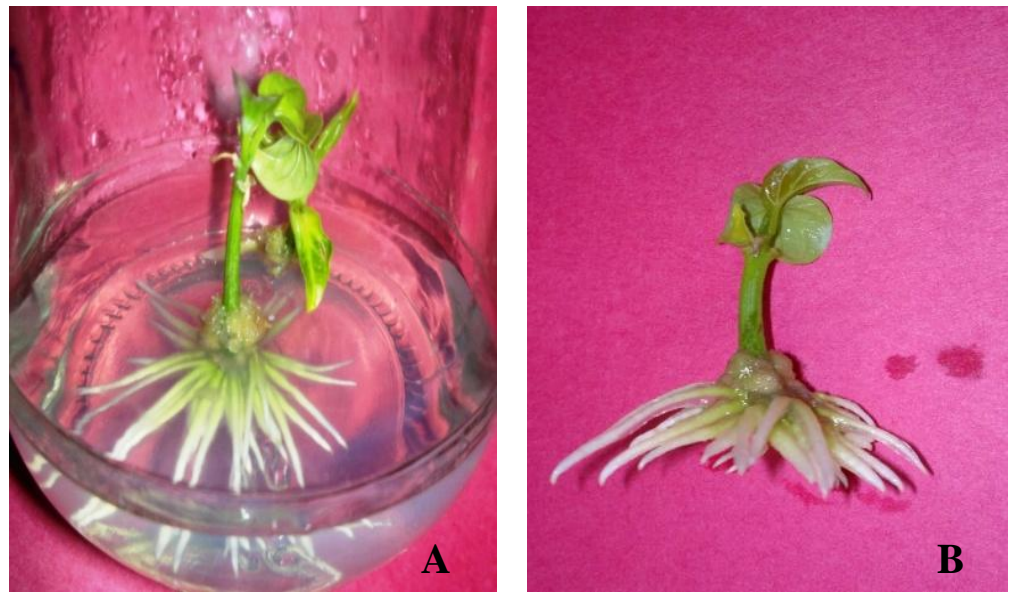

Plate.2 (A) Root induction on rooting medium, (B) Complete plant before hardening
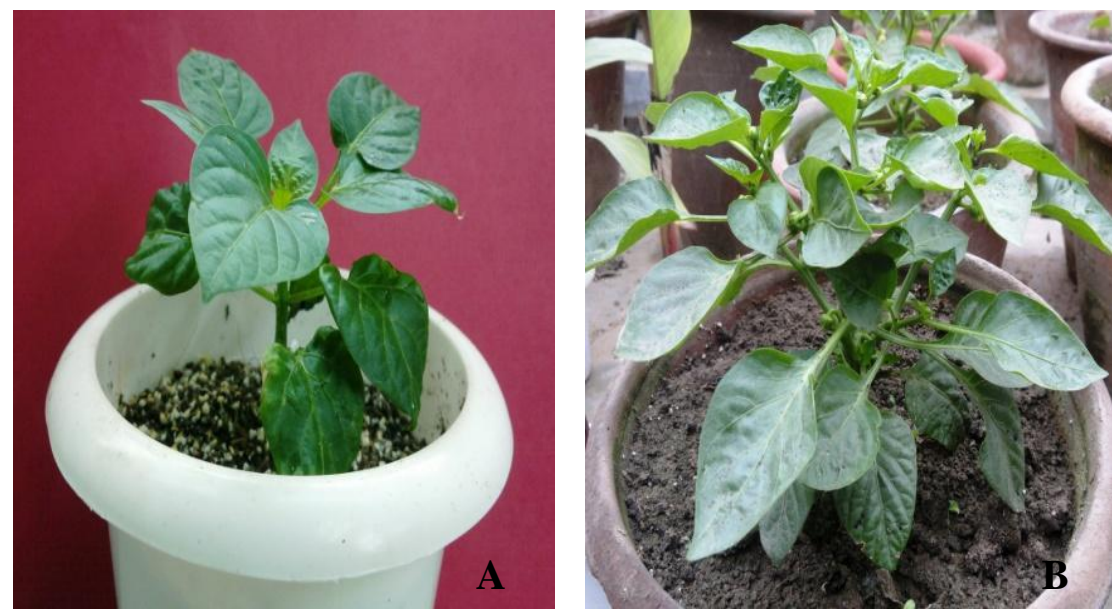

Plate.3 (A) Initial hardening of regenerated plantlets and, (B) Hardened plants of capsicum grown in pots 
Plant hormones play a crucial role in controlling the plants growth and development. Both auxins and cytokinins are synergistically required to induce cell division and growth in plant tissue cultures. In the study, BAP, kinetin, TDZ and zeatin along with $\mathrm{GA}_{3}$ were used for developing efficient in vitro plant regeneration in selected capsicum hybrids Bharat and Indra. Among the cytokinins tested, zeatin followed by kinetin, was found superior with maximum per cent shoot elongation but minimum was observed in thidiazuron (TDZ). Inhibition of shoot elongation is a common problem with TDZ and it may be consistent with its superoptimal cytokinin activity, whereas the presence of a phenyl group in TDZ might be the possible cause of shoot-bud fasciation (Huetteman and Preece, 1993; Steinitz et al., 2003). In the study, shoot buds induced from explants on a medium containing TDZ, did not elongate properly and resulted in a rosette of shoots when continued to be cultured on the same medium. Thus, in order to elongate the shoot, it needs to culture the explants on medium containing TDZ along with $\mathrm{GA}_{3}$.

Among plant growth regulators concentrations, BAP, kinetin and zeatin at 7.5 and $10.0 \mathrm{mg} / \mathrm{l}$ along with $2.0 \mathrm{mg} / \mathrm{G} \mathrm{GA}_{3}$ and TDZ at $5.0 \mathrm{mg} / \mathrm{l}$ along with $2.0 \mathrm{mg} / \mathrm{l} \mathrm{GA}_{3}$ gave good response in all the explants studied in both the hybrids. The higher concentrations of TDZ lead to death of explants (Table 4). The growing medium supplemented with 7.5 $\mathrm{mg} / \mathrm{l}$ zeatin along with $2.0 \mathrm{mg} / \mathrm{l} \mathrm{GA}_{3}$ recorded maximum per cent regeneration $(78.9 \%)$, more number of elongated shoots per explant (2.4) and highest per cent shoot elongation $(65 \%)$ in cotyledon explants of hybrid Indra having abaxial side in contact with medium (Plate 1B) and in hybrid Bharat same medium reported maximum per cent regeneration (75.7\%), more number of elongated shoots per explant (2.4) and highest per cent shoot elongation $(64.7 \%)$ on cotyledon explants having abaxial side in contact with growing medium (Table 5). A higher concentration of BAP at $10.0 \mathrm{mg} / \mathrm{l}$ was used by Ebida and $\mathrm{Hu}$ (1993) to proliferate multiple shoots from cut surfaces of capsicum hypocotyls. Christopher and Rajam (1994) observed maximum shoots on MS medium with BAP at $88.8 \mu \mathrm{M}$ or kinetin at $116.2 \mu \mathrm{M}$. Regeneration from cotyledonary explants of chilli was obtained by Shivegowda et al., (2002) on MS medium supplemented with zeatin 9-18 $\mu \mathrm{M}$ in combination with $\mathrm{GA}_{3}(2.89 \mu \mathrm{M})$. Nancy et al., (2005) observed multiple shoots from Habanero pepper with nodes cultured on MS medium supplemented with $3.4 \mu \mathrm{M}$ TDZ. Sanatombi and Sharma (2008) obtained maximum number of shoots in shoot-tip of Capsicum chinense Jacq. cv. Umorok, on medium containing 91.2 $\mu \mathrm{M}$ BAP and 31.1 $\mu \mathrm{M}$ TDZ with 4.7 $\mu \mathrm{M}$ Kinetin. Shoot multiplication in four chilli cultivars was obtained in MS medium with $6.0 \mathrm{mg} / \mathrm{l} \mathrm{BAP}$, $1.0 \mathrm{mg} / \mathrm{l}$ kinetin and $0.5 \mathrm{mg} / \mathrm{l} \mathrm{GA}_{3}$ (Ranjan et al., 2010). Khurana et al., (2011) developed a method of plant regeneration in male sterile line MS-12 of chilli on MS media supplemented with $9.0 \mathrm{mg} / \mathrm{l} \mathrm{BAP}, 2.0 \mathrm{mg} / \mathrm{l}$ kinetin and $2.0 \mathrm{mg} / \mathrm{l}$ IAA. Dafadar et al., (2012) obtained maximum number of shoots per leaf explants on medium containing 8.87 $\mu \mathrm{M}$ BAP and $2.85 \mu \mathrm{M}$ IAA. Rahul et al., (2015) obtained more numbers of shoot buds from Naga chili in MS medium containing 5 $\mathrm{mg} / \mathrm{l} \mathrm{BAP}$ and $0.5 \mathrm{mg} / \mathrm{l}$ IAA.

Root induction was done by sub-culturing the shoots on MS medium supplemented with 0.5 $\mathrm{mg} / \mathrm{l}$ IBA. Cent per cent rooting was observed in regenerated shoots of capsicum hybrids Bharat and Indira on MS medium containing $0.5 \mathrm{mg} / 1 \mathrm{IBA}$ (Plate 2). MS medium with IBA at $0.1 \mathrm{mg} / \mathrm{l}$ was used for root induction of pepper by Agarwal et al., (1989). Garcia and Bahilla (1990) and Arroyo and Revilla (1991) proposed supplementation of the rooting medium with IBA at $0.05 \mathrm{mg} / \mathrm{l}$ and NAA at 
$0.1 \mathrm{mg} / \mathrm{l}$. Rahul et al., (2015) achieved shoot elongation and rooting in MS basal medium.

Plantlets with well developed roots were transferred to pots containing sterile mixture of coco-peat and vermiculite (1:1) and kept under culture room for hardening (Plate 3A). After 14 days of acclimatization under laboratory condition, plantlets were transferred to shade net in big size pot containing 1:1:1 mixture of soil: sand: farmyard manure (Plate 3B). Similarly, In vitro rooted pepper plants were acclimatized soil: vermiculite 50:50 v/v mix (Christopher and Rajam, 1994), perlite: soil 1:1 mix (Szasz et al., 1995) and then transferred to soil for establishment and grow as normal plant.

The present investigation showed that plant regeneration is highly dependent on genotypes, type of explants, plant growth regulators. Hence, before conducting the transformation experiment or experiments on creation of somaclonal variation or in vitro selection etc., it becomes necessary to standardize the regeneration system for the targeted genotypes. Here, an efficient and reproducible regeneration protocol using capsicum hybrids Bharat and Indra was developed, which can be exploited for mass production and further research.

\section{References}

Agarwal, S., Chandra, N. and Kothari, S.L. 1989. Plant regeneration in tissue cultures of pepper (Capsicum annuum L. cv. Mathania). Plant Cell, Tissue and Organ Culture, 16: 47-55.

Andreoli, C. and Khan, A.A. 1999. Matriconditioning integrated with GA to hasten germination and improve stand establishment of pepper and tomato seeds. Brazilian J. Agri. Res., 34(10): 1953-1959.

Arroyo, R. and Revilla, M.A. 1991. In vitro plant regeneration from cotyledon and hypocotyl segments in two bell pepper cultivars. Plant Cell Reports, 10: 414416.

Christopher, T. and Rajam, M.V. 1996. Effect of genotype, explant and medium on in vitro regeneration of red pepper. Plant Cell, Tissue and Organ Culture, 46: 245-250.

Christopher, T. and Rajam, M.V. 1994. In vitro clonal propagation of Capsicum spp. Plant Cell, Tissue and Organ Culture, 38: 25-29.

Dabauza, M. and Pena, L. 2001. High efficiency organogenesis in sweet pepper (Capsicum annuum L.) tissues from different seedling explants. Plant Growth Regulation, 33: 221-229.

Dafadar, A., Das, A., Bandyopadhyay, S. and Jha, T.B. 2012. In vitro propagation and molecular evaluation of a Capsicum annuum L. cultivar with a high chromosome number $(2 n=48)$. Scientia Horticulturae, 140: 119-124.

Ebida, A.I.A. and $\mathrm{Hu}, \mathrm{C} . \mathrm{Y} .1993$. In vitro morphogenetic responses and plant regeneration from pepper (Capsicum annuum L. cv. Early California Wonder) seedling explants. Plant Cell Reports, 13: 107-110.

Egea, C., Dickinson, M.J., Candela, M. and Candela, M.E. 2002. $\beta$-1,3-glucanase isoenzyme and genes in resistant and susceptible pepper (C. annuum) cultivars infected with Phytopthora capsici. Physiologia Plantarum, 107: 312-318.

Ezura, H., Nishimiya, S. and Kasumi, M. 1993. Efficient regeneration of plants independent of exogenous growth regulators in bell pepper (Capsicum annuum L.). Plant Cell Reports, 12: 676-680.

Garcia, R.A. and Bahillo, M.A.R. 1990. Tissue and cell culture of pepper (Capsicum annuum L. cv. Pico and $c v$. 
Piquillo). Actas De Horticulturae, 280: 249-254.

Groot, S.P.C. and Karssen, C.M. 1987. Gibberellins regulate seed germination in tomato by endosperm weakening: a study with gibberellin-deficient mutants. Planta, 171: 525-531.

Huetteman, C.A. and Preece, J.E. 1993. Thidiazuron: A potent cytokinin for woody plant tissue culture. Plant Cell Tissue and Organ Culture, 33: 105-119.

Khurana, D.S., Kannanghara, K.N., Devi, R. and Gosal, S.S. 2011. In vitro clonal propagation of a male sterile line in chilli crop. Vegetable Sci., 38(2): 123127.

Kumar, O.A. and Tata, S.S. 2010. In vitro Shoot bud differentiation from hypocotyl explants of chili peppers (Capsicum annuиm L.). Notulae Scientia Biologicae, 2(1): 66-69.

Kumar, R.V., Sharma, V.K., Chattopadhyay, B. and Chakraborty, S. 2012. An improved plant regeneration and Agrobacterium-mediated transformation of red pepper (Capsicum annuиm L.). Physiol. Mol. Biol. Plants, 18(4): 357-364.

Marta O. and Pawel, N. 2015. In vitro plant regeneration of 4 Capsicum spp. genotypes using different explant types. Turkish J. Biol., 39: 60-68.

Mathew, D. 2002. In vitro shoot and root morphogenesis from cotyledon and hypocotyls explants of hot pepper cultivars Byadgi Dabbi and Arka Lohit. Capsicum and Eggplant Newsletter, 21: 69-72.

Mok, S.H. and Norzulaani, K. 2007. Trouble shooting for recalcitrant bud formation in Capsicum Annuum var. Kulai. Asia Pacific J. Mol. Biol. Biotechnol., 15(1): 33-38.

Nancy, S.B., Adriana, C.F., Felipe, B.P., Maria, C.M.P., Patricia, Y.Z.C., Anabel, S. R., Amilcar, Z.C., Omar, G.A. and
Maria, L.M.H. 2005. Regeneration of Habanero pepper (Capsicum chinense Jacq.) via organogenesis. HortSci., 40(6): 1829-1831.

Ochoa, N.A. and, Ramirez, M.R. 2001. In vitro chilli pepper biotechnology. In Vitro Cellular and Developmental Biol. Plant, 37: 701-729.

Rahul, P., Raj, Glint, V.D., Nirmal Babu, K. 2015. In vitro plant regeneration in Capsicum chinense Jacq. (Naga Chili). J. Appl. Biol. Biotechnol., 3(01): 030033.

Ramirez, R.M. and Ochoa, N.A. 1996. An improved and reliable chilli pepper (Capsicum annuum L.) plant regeneration method. Plant Cell Reports, 16: 226-231.

Ranjan, J.K., Singh, S.K., Chakrabarti, A.K. and Pragya, 2010. In vitro shoot regeneration from cotyledonary leaf explants in chilli and bio-hardening of plantlets. Indian J. Horticulture, 67(1): 43-49.

Sanatombi, K. and Sharma, G.J. 2008. In vitro propagation of Capsicum chinense Jacq. Biologia Plantarum, 52(3): 517-520.

Shivegowda, S.T., Mythili, J.B., Lalitha, A., Saiprasad, G.V.S., Gowda, R. and Gowda, T.K.S. 2002. In vitro regeneration and transformation in chilli pepper (Capsicum annuит L.). $J$. Horticultural Sci. Biotechnol., 77(5): 629-634.

Simonne, A.H., Simonne, E. H., Eitenmiller, R.R., Mills, H.A. and Green, N.R. 1997. Ascorbic acid and provitamin A contents in unusually colored bell peppers (Capsicum annuum L.). Food Components Analysis, 10: 299-311.

Steinitz, B., Kusek, M., Tabib, Y., Paran, I. and Zelcer, A. 2003. Pepper (Capsicum annuит L.) regenerants obtained by direct somatic embryogenesis fail to develop a shoot. In Vitro Cellular and Developmental Biol. Plant, 39: 296- 
303.

Suzuki, K. and Mori, M. 2003. Carotenoid composition of new cultivar of Capsicum annuum during maturation and its high capsanthin content. $J$. Japanese Soc. Food Sci. Technol., 50: 324-326.

Szasz, A., Nervo, G. and Fari, M. 1995. Screening for in vitro shoot-forming capacity of seedling explants in bell pepper (Capsicum annuиm L.) genotypes and efficient regeneration using thidiazuron. Plant Cell Reports, 14(10): 666-669.

Valadez, B.M.G., Aguado S.G.A., Carrillo, C.G., Aguilar, R.V.H., Espitia, R.E., Montes, H.S. and Robledo, P.A. 2009. In vitro propagation and agronomic performance of regenerated chilli pepper (Capsicum spp.) plants from commercially important genotypes. In Vitro Cellular and Develop. Biol. Plant, 45: 650-658.

Venkataiah, P., Christopher, T. and Subhash, K. 2003. Thiadiazuron induced high frequency adventitious shoot formation and plant regeneration in Capsicum annuum L. J. Plant Biotechnol., 5: 245250.

Watkins, J.T. and Cantlife, J.D. 1983. Hormonal control of pepper seed germination. HortSci., 18(3): 342-343.

Watkins, J.T., Cantlife, J.D., Huber, D.J. and Nell, T.A. 1985. Gibberellic acid stimulated degradation of endosperm in pepper. J. American Soc. Horticultural Sci., 110: 61-65.

\section{How to cite this article:}

Vivek Hegde, P.S. Partap and Yadav, R.C. 2017. In Vitro Regeneration of Capsicum (Capsicum annuum L.) from Cotyledon Explants. Int.J.Curr.Microbiol.App.Sci. 6(5): 225-237. doi: http://dx.doi.org/10.20546/ijcmas.2017.605.026 